\title{
Patterns of Mental Healthcare Provision in Urban Areas: A Comparative Analysis for Informing Local Policy
}

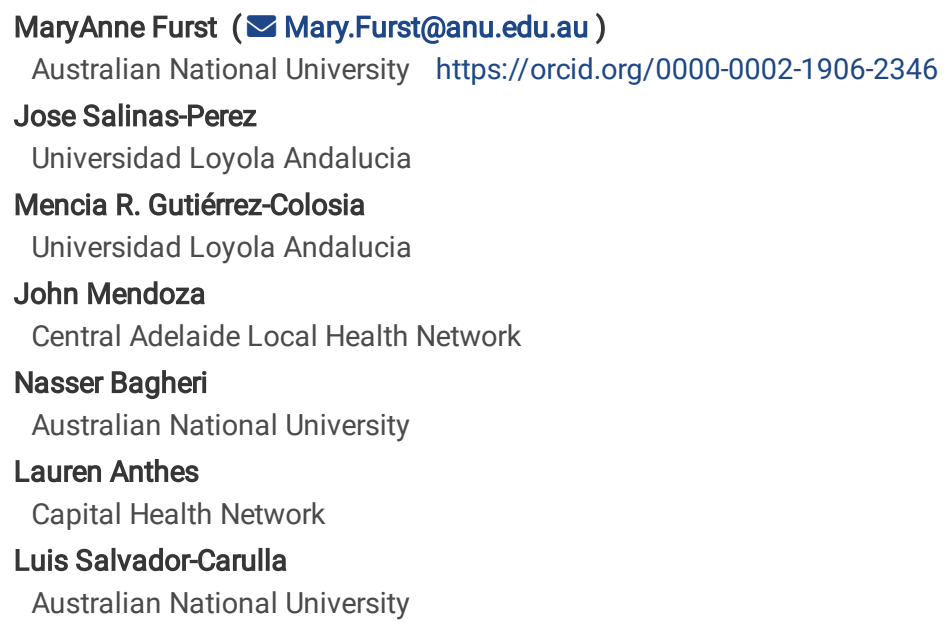




\section{Abstract}

Objective

Urbanisation presents specific challenges for the mental wellbeing of the population. An understanding of availability of existing service provision in urban areas is necessary to plan for the needs of people with mental illness in these contexts to identify gaps in care provision and inform policy and planning. This study aims to provide an analysis of the availability and diversity of mental health care in urban areas in Australia , and compare it with benchmark areas in Europe (Finland and Spain) and South America (Chile).

Method

DESDE-LTC, an instrument for service classification and description of services providing long term care was used to analyse and compare service provision in Australia (Australian Capital Territory (ACT)), to other urban areas in Australia (Western Sydney, Perth North and South East Sydney) and to benchmark areas in other countries (Spain, Finland and Chile), using a standard healthcare ecosystems approach. Services from all relevant care sectors were calculated per 100,000 adults.

Results

We identified commonalities in the pattern of mental health care in urban regions in Australia when compared to urban regions internationally, as well as gaps in care provision common to all study areas.

Conclusion

These results highlight the relevance of an ecosystems approach to service planning in mental health care at the local level, and the use of a standardised instrument able to provide valid comparisons. There is a need for models of care sensitive to mental health care ecosystem indicators.

\section{Introduction}

Urbanisation presents a specific set of challenges to the planning and provision of mental health services. It is associated with a higher prevalence of psychiatric disorders (Lederbogen et al., 2011), including anxiety and depression (Peen et al., 2010) and psychotic disorders (Frank et al., 2004; Kirkbride et al., 2018; Krabbendam \& van Os, 2005; Pedersen \& Mortensen, 2001). Psychosocial stressors in urban environments such as infringement of personal space, exposure to crime, increased social competition, social fragmentation (Bagheri et al., 2019) and the effect of high density and/or high rise living, negatively affect mental wellbeing (Helbich et al., 2018; van den Berg et al., 2016); increase the incidence of depression (Tomita et al., 2017) and suicide rates (Helbich et al., 2018); while the relative availability of walkability and urban green space (Astell-Burt \& Feng, 2019) have an impact on social cohesiveness (Kuo et al., 1998), and other enablers of mental wellbeing such as participation in physical activity (Bixby et al., 2015). Global strategies on urban mental health care have been included in the ICircle declaration (I-CIRCLE, n.d.), and Cities Rise (Underhill C, 2018).

People living in urban areas comprise $90 \%$ of the population in Australia, $80.3 \%$ in Spain $85.4 \%$ in Finland and $87.6 \%$ in Chile (2018 Revision of World Urbanization Prospects / Multimedia Library - United Nations Department of Economic and Social Affairs, n.d.; Australia Urban Population Percent Of Total, n.d.). There is a need for a proper assessment of the availability of mental health care to these populations within the context of the particular challenges posed by urbanisation. Additionally, standardised comparison of urban service provision between and within countries can assist in monitoring the impact of policy actions and reforms, identify inequities in availability, and facilitate the sharing of knowledge and best practice. This analysis should be made separately for the different contexts of urban and rural environments(Perkins et al., 2019).

However, system complexity and terminological variability in mental health care create the risk of ecological fallacy and conceptual ambiguity in mental health research. A common reference framework (Leginski et al., 1989) and a consensus on terminology are needed to avoid these pitfalls and enable valid comparisons (Montagni et al., 2018; Luis Salvador-Carulla et al., 2013). Standardised empirical data is necessary to identify service provision in an area, provide the tools for efficient system navigation, and facilitate comparison and knowledge sharing between providers (Leginski et al., 1989; L. Salvador-Carulla et al., 2006).

Mental Health Ecosystems Research (MHESR) is a new approach to the study of complex health systems. Using a whole systems approach, MHESR provides an analytical framework for the diversity and variation in levels and types of care in and between mental health systems and countries (Lora et al., 2017), and the local social, economic, demographic and political contexts in which they operate (Furst et al., 2019). From this, the structure of the whole service system in a particular area can be envisioned, showing patterns of care delivery, the relationship of the pattern of service provision with social determinants of health, gaps and duplications in service availability, and providing a basis for comparison with other systems (Romero-LópezAlberca et al., 2019).

Within this context, this study provides an analysis of the availability and diversity of mental health care in a reference urban area in Australia (Australian Capital Territory (ACT)), using a standardised classification tool, and compares it to other urban areas in Australia, and to benchmark areas in Europe and South America that have been coded and mapped with the same system (Romero-López-Alberca et al., 2019) It follows the previous analysis of patterns of care in rural areas in Australia as part of the Glocal (Global-Local) Atlas project (GLOCAL / Research School of Population Health, 
n.d.; J.-A. Salinas-Perez et al., 2020) which identified significant variations between states and between neighbouring areas within states (van Spijker et al., 2019). We ask the following questions:

- Can we identify and compare global patterns of mental health provision across urban areas? and

- Can these patterns inform local policy and planning?

\section{Methods}

This study follows a healthcare ecosystem approach for the standard evaluation of the patterns of care provision across different health districts(Furst, M.C et al., 2020).

Catchment area: The regions in this study have all been classified as urban according to OECD typology(OECD_regional_typology_Nov2012.Pdf, n.d.). This typology takes into account the percentage of the population living in small areas and municipalities defined as predominantly rural within the region (Refinement of the OECD Regional Typology: Economic Performance of Remote Rural Regions, n.d.).

The population in the four selected urban Australian areas is between 400,000 and 1.5 million. The regions span the continent, with Perth North (PN) on the western seaboard, and South East Sydney (SES) and Western Sydney (WS) on the east coast. Australian Capital Territory (ACT) is home to the national capital, Canberra. Mental health services in all Australian health regions are provided by a combination of state funded public organisations and Non-Government Organisations (NGOs).

The population in the three urban international regions is between 290,000 and 1.65 million. Talcahuano is one of 28 autonomous Health Districts in Chile. Most of these districts are organised by defined mental health catchment areas areas where publicly funded care provision is coordinated by a single reference community MH centre. Gipuzkoa is a province in the Basque Autonomous Community in Spain with 13 mental health catchment areas. In Spain, healthcare is also publicly funded and is devolved to its 17 autonomous communities. Primary care provides the gateway to more specialised mental health care when needed. The Helsinki-Uusimaa region (herein "Helsinki") in Finland comprises 26 municipalities and includes the capital, Helsinki. Municipalities in Finland are responsible for health and social care services, which are also tax funded and may join to form hospital districts for more specialised mental health care.

Socio-economic and socio-demographic data from the Australian regions were collected from Australian Bureau of Statistics (ABS) and Public Health Information Development Unit (PHIDU), and mapped with services distribution at different levels of aggregation(Research School of Population Health, 2019). Data from the European regions and Chile were obtained from previous studies using population statistics collected from their national institutes(Gutiérrez-Colosía et al., 2017; Iruin A, et al., 2013; Sadeniemi et al., 2018; J. A. Salinas-Perez et al., 2018).

\section{Measure}

The measure used for data collection in all studies was the DEscription and Evaluation of Services and DirectoriEs for Long Term Care( DESDE-LTC), an internationally validated instrument for the standard description and coding of services (Luis Salvador-Carulla et al., 2013). Its taxonomic structure and use of operational definitions of units of care addresses the two main methodological problems in services research: terminological variability (different terms may be used for the same type of service and vice versa) and a commensurability bias (different units of analysis may be used which do not provide true like for like comparison)(Luis Salvador-Carulla et al., 2015). DESDE-LTC is a multiaxial system that classifies and codes the target population and type of care provided by services in all relevant sectors using a classification tree which bifurcates from six initial branches (Residential, Outpatient, Day Care, Self- help and Voluntary Care, and Information and Assessment, and Accessibility to services) to provide 25 clusters grouping similar typologies of care according to characteristics such as acuity, mobility, and intensity of service provision. Its units of analysis are professional teams with organisational and temporal stability (described as Basic Stable Inputs of Care or BSICs), and the Main Type of Care they provide (MTCs). The use of these lowest units of production of care as a common unit of analysis enables cross country and cross regional comparison of service provision at the local level.

Inclusion criteria for services were as follows:

1. The service targets people with a lived experience of mental illness; including any diagnosis of mental disorders (ICD-10, section F);

2. The service is universally accessible: without significant out-of-pocket expenses or under a fully private insurance scheme);

3. The service is within the boundaries of the study region;

4. The service provides direct care or support to consumers.

\section{Data collection}

In all cases, data collection was made in collaboration with the local and regional public agencies. Services were identified through information provided in consultation with officers from these agencies and relevant peak bodies, and through web searches. Following ethics approval, all service organisations located in ACT providing support to people with mental illness were contacted and the managers of participating organisations interviewed, either face to face or by telephone. Data was manually collected in 2016 and verified on a broad set of characteristics of multisectoral care provision for the target population group(Furst et al., 2018). Service data was coded using the DESDE-LTC tool, and presented visually through the use 
of maps and other visual analytics tools. From this, an Integrated Atlas of Mental Health was developed, which included evidence from the local context such as socio-demographic and socio-economic indicators. Data was analysed and revised following review of the data by expert local planners.

\section{Data comparison and analysis}

The Australian National University (ANU), together with Psicost Research Association and Andalucia Loyola University (Spain) have developed a data repository of the information on local service provision collected worldwide using the ESMS/DESDE classification system and standard methods of data collection This repository allows the analysis of patterns of service provision in a given area in comparison to other areas previously mapped with the same method and instrument, and checked by the same core group. In this case, we compare the ACT reference urban area with information available in the Glocal MH Atlas repository from the other six areas: Western Sydney (Salvador-Carulla L, et al., 2016), South Eastern Sydney (Furst, M.C.; et al., 2016), Perth North (Furst M, et al., 2018), Helsinki (Helsinki-Uusimaa), Finland (Gutiérrez-Colosía et al., 2017; Sadeniemi et al., 2018),Gipuzkoa, Spain (Iruin A, et al., 2013) and Talcahuano, Chile (J. A. Salinas-Perez et al., 2018; Luis Salvador-Carulla et al., 2008).

The availability, placement capacity and diversity of service provision was analysed according to the Main Types of Care provided by services(BSICs). Availability is defined as a service being operable upon demand to perform its designated or required function; placement capacity is defined as the maximum number of beds in residential care; and diversity as the number of different types of individual Main Type of Care identified. The availability rate for each Main Type of Care was calculated per 100,000 adults of the target population. Data was coded according to the DESDE-LTC coding system, although here we have not included Information and Assessment services or Self-help and Volunteer services. Additionally, the European and Chilean studies did not include accessibility services, as this function is included in the role of other teams in these countries and not designed as separate services.

\section{Results}

\section{Socio-demographic indicators}

Socio-economic and socio-demographic indicators are shown in full in Table 1 and summarised below.

ACT has an area of $2,351 \mathrm{~km}^{2}$ with a population of 403,468 , most of whom live in Canberra, its only city. Within Australia, ACT and South East Sydney were relatively socio-economically advantaged, while Western Sydney had highest levels of socio-economic disadvantage. Despite this, rates of psychological distress and of suicide in ACT were the second highest nationally and while WS had the highest rate of psychological distress, it had the lowest suicide rate. The international centres experienced higher suicide rates than all Australian regions except PN, as well as higher unemployment, particularly in the case of Gipuzkoa. Helsinki, with the highest suicide rates in the study, also had the most people living alone, and single parent families.

\section{Service availability}

\section{Overview (figure 1).}

ACT provided more community based residential care and less hospital care than the other Australian areas, and was second overall only to Finland in availability of the former. All Australian regions provided lower rates of day care than all the international regions, particularly Spain. In outpatient care, social outreach type care, and centre based health care such as community mental health centres were the most available types of care in the Australian regions, particularly in ACT. Outpatient care of all types was less available in the international regions, and where available it was more commonly centre based rather than outreach. ACT provided higher rates of services co-ordinating or providing access to care than the other Australian regions, but this type of care was not included in the international comparison as in these other regions, it is typically included in other types of care rather than provided as a separate service.

Residential Care: a comparison of the availability and bed capacity of residential Care per 100,000 adult residents between ACT, Perth North, Western Sydney, South East Sydney, Talcahuano, Gipuzkoaand Helsinki is shown in Figure 2.

Australian comparison. ACT provided the second lowest rate of acute hospital care of the Australian districts (1.44 Main Types of Care and 22.74 beds per 100,000 residents over17 years old) after Western Sydney, with Perth North providing the highest (2.11 Main Types of Care and 26.28 beds per $100,000)$. Hospital care available in all Australian regions was significantly more acute than non-acute. ACT was the only Australian region not to provide non-acute hospital care. Perth North was the only district to provide alternatives to hospitalisation, although at a low level of intensity (e.g. crisis homes: 0.15 Main Types of Care per 100,000 adults). ACT provided significantly more residential community care in terms of services than the other districts (a total of 5.42 Main Types of Care and 30.68 beds per 100,000 adults), compared to South East Sydney (0.15 Main Types of Care per 100,000 adults) and Western Sydney (2.26 Main Types of Care and 11.98 beds per 100,000 adults). However, bed capacity was higher in Perth North (70.99 beds per 100,000 adults) than ACT. Community residential care in Perth North was provided largely by hostel type accommodation.

International comparison. The number of hospital based services was lower in the Spanish and Chilean regions than in all Australian districts, and it was highest in Finland. Spain and Finland provided more non-acute than acute hospital care, with Helsinki having the highest bed capacity, while the 
Chilean region provided acute hospital care only. Alternatives to hospitalisation were only available in Helsinki, again at a low rate. Community based residential care in ACT was higher than that in Chile, similar to Spain but lower than Finland, which also had the highest overall rate of residential care.

\section{Day Care.}

A comparison of the availability and placement capacity of day Care per 100,000 adult residents between ACT, Perth North, Western Sydney, South East Sydney, Talcahuano, Gipuzkoaand Helsinki is shown in Figure 3.

Australian comparison. Acute health-related day Care was not available in any of the Australian health districts, and ACT was the only Australian district to provide any health-related day Care. ACT had the second highest provision of social type day Care after South East Sydney but along with Perth North, it had no work-related day Care.

International comparison. Health and work-related day Care was more available in all three international regions, especially Spain, than in ACT where it was not available at all.

\section{Outpatient Care}

A comparison of the availability of outpatient Care per 100,000 adult residents between ACT, Perth North, Western Sydney, South East Sydney, Talcahuano, Gipuzkoa and Helsinki is shown in Figure 4.

Australian comparison. Outpatient Care was more health than social related in ACT and all Australian regions except Perth North. Health-related outpatient Care in ACT, as in the other Australian districts, was predominantly non-acute, and ACT had a higher rate of centre based non-acute services such as psychological counselling. The rate of mobile or outreach social type care was similar in all Australian regions.

\section{International comparison.}

All Australian regions provided more health-related outpatient Care than all international regions. The only type of health-related outpatient Care available in the Spanish and Chilean regions was centre based (non-mobile) care, which was also the most available type of outpatient Care in ACT. Outpatient care provided by sectors outside the health sector was not available at all in the Spanish and Chilean regions and only available in the Finnish region at a much lower rate than in any of the Australian regions.

Accessibility. Accessibility Care or services providing access to other types of care rather than providing direct care themselves was not assessed in the international studies. However, in Australia, case co-ordination type accessibility Care was significantly more available in ACT than in the other areas (Figure 1), while it provided less of the other types of accessibility care (e.g. to employment, housing).

\section{Service Diversity-National (Australia)}

In Australia, ACT provided the lowest number of types of care but the second highest diversity of service types, while Perth North provided the highest number and diversity of Main Types of Care Western Sydney provided a similar number of Main Types of Care to ACT but with lower diversity (Table 2).

\section{Discussion}

The socio-economic and socio-demographic characteristics of the regions in the study suggest a complex relationship with service availability and the need for this information to be readily available for appraisal by local planners, as well as its usefulness in service system comparison: for example the relevance of different models of community living in northern and southern Europe to the delivery of residential care; or the testing of equity of access by comparison of service availability in relation to population size or disadvantage.

The pattern of service availability within Australia was broadly similar between the regions, with our reference area, the ACT, conforming to this pattern in most categories except residential community care, where it more closely resembled that of the international regions. The provision of residential care in all regions in Australia however, was skewed in favour of the provision of acute hospital inpatient care. Likewise, there was a similarity between all Australian regions in the range of different types of care available, despite differences in overall number of services, suggesting that the more specific needs of minority or marginal groups may not be being met, and highlighting the importance of understanding of the local context in service planning.

The pattern of care delivery we identified in Australia differed from that of the international regions, with day care, especially work and health related day care being a more significant component of the care systems in international regions: for example Talcahuano, with a much lower overall rate of services than ACT, nevertheless still provided a higher rate of day care. Conversely, outpatient services in the community providing psychosocial (as distinct from health related) care, a category of service largely absent in the international regions, were a significant component of the pattern of care in Australia. The main differences between the three international regions were the overall much lower rate of services in Talcahuano; the higher availability of residential care overall in Helsinki-Uusimaa; and the higher availability of health and work related day care in Gipuzkoa.

A characteristic of all systems in the study was a paucity or lack of alternatives to hospitalisation; and a lack of sub-acute residential care in all regions except Helsinki-Uusimaa. This suggests that acute inpatient care, despite being intended for the small number of people with severe illness 
(Department of Health, 2017), could be filling these gaps, both for people in crisis, and for those who are no longer acute but still require a level of subacute residential support, particularly in the Australian regions where it comprises a larger part of the overall system . Length of stay in fulltime hospitalisation has been shown to correlate negatively with the development of alternatives to fulltime hospitalisation in the local context (Gandré et al., 2017). The lack of day care services in the Australian regions may also increase the need for inpatient care, as availability of day care services may play a role in reducing hospitalisation, maintaining health and promoting community participation through (i) the provision of alternatives to hospitalisation in the case of acute health related day services; and (ii) through assistance with skills training and education in the case of work related and structured day services. (Recovery-Oriented-Community-Mental-Health-Models-SAX-REPORT.Pdf, n.d.; Sanches et al., 2019)

The urban regions in Europe and Chile provide less outpatient care than in any Australian region but significantly more health and social related day services: it may be that day support, which is more often provided on a group basis, providing skills development and social participation, also reduces the need for one to one type outpatient care. The higher level of mobility in the Australian regions of outpatient social (non-health related) type support merits further investigation as to its efficiency. This type of care is commonly provided as individual support for people with moderate to severe illness: support which may be being provided more efficiently as group type care in the other regions by day centres.

The higher rate of accessibility services in ACT compared to the other Australian regions could be an indicator of increased system complexity associated with a high rate of Non-Government Organisations leading to more complex pathways of care (Furst et al., 2018) It is important to note that in many other countries, this type of service is more commonly incorporated into other types of care. A pattern of care like that in Australia which separates the accessibility function from other service provision hinders integration of care through the addition of an extra layer of services between those providing direct care provision.

\section{Rural-urban comparison}

Comparison of these results with a previous study on rural service availability in Australia, shows a higher level of supported accommodation such as group homes in urban than in rural areas; a lower rate of acute residential care and a higher rate of day care services (van Spijker et al., 2019). It has been suggested that the high rate of acute residential care in rural areas could be due to delayed help seeking caused by factors such as distance, or work (farming) commitments. On the other hand, there could be a higher tendency to admit a patient where there is any doubt about the availability or accessibility, including distance accessibility, of ongoing community care in rural and remote areas. Lower availability of day care services in rural areas may not be surprising given the distance to travel for a regular day service could often be prohibitive.

\section{Implications}

This study has shown the importance of standardised comparisons both within and between countries in identifying gaps, commonalities and differences in care provision to inform planning. This system level understanding of the complexity of systems and of patterns of care is important to planning in urban areas, and required by groups such as iCircle which are engaged with ways of promoting the mental health of people in cities. Planners in local health jurisdictions, such as the PHNs in Australia, need to have an understanding of the gaps or duplications in service provision in their area in the context of local need if they are to plan efficient and appropriate service delivery. The significance of this type of data is evidenced by its citation in local strategic documents(CHN-Mental-Health-and-Suicide-Prevention-Plan.Pdf, n.d.), and the co-operation in our ACT study of local health organisations responsible for planning and/or commissioning services including ACT Health, the Capital Health Network, and the Office of Mental Health and Wellbeing, with a representative of the Capital Health Network co-authoring this study. The Atlas project is the first work that provides this type of co-operation between policy makers and planners and researchers.

The heterogeneity of local systems at the meso or local area level, including the specific needs and patterns of care delivery of urban areas and differences between urban and rural patterns of care, should be taken into account in policy at the macro level. Knowledge of service availability at local or regional network level is important in planning or monitoring policy changes and reform. For example, policy strategies such as integrated care, or in Australia the stepped care policy (Department of Health, 2017) assume a comprehensive availability of services. Yet the current availability of this level of service provision even in urban areas, where there are multiple specific challenges to mental wellbeing and where due to population concentration, service provision might be expected to be at its highest within countries, is not indicated by these results. These comparisons can also identify equity issues, and investigate commonly neglected types of care such as alternatives to hospitalisation across areas or unexpected differences between urban areas in the same country.

Health experts including planners and policy makers have identified the usefulness of visual tools and analytics but require that it should be simple and readily available(Walsh et al., 2020). Data visualisation of complex phenomena such as patterns of service provision enables pattern recognition, and the rapid identification of similarities and differences between the regions and gaps in service provision. The use of a coding system to simplify complex data, assists in the development of more readily accessible visual analytics.

Another key finding of the study is the usefulness of repositories, such as that cited in this study and of others such as the EU Compass (European Commission, 2016) collecting data and other policy and stakeholder activity information in Europe, for the collection, organisation and comparison of relevant information for mental health care planning.

\section{Limitations}


The results are limited to seven international urban areas although the comparisons available using the same taxonomy and method are extensive. Taking into account the variability in the definition of urban areas, we opted for using the population density cut-off point provided by OECD.

(Refinement of the OECD Regional Typology: Economic Performance of Remote Rural Regions, n.d.) Some of the urban areas include natural parks and reserves so their actual population density is higher. As full data are available from these regions other approaches to urbanicity can be used in the data analysis. Data collection was conducted at different points of time in a four year period (2012-2016). Within this time frame, the development of new local services has a low impact in the comparison across different jurisdictions even within the same system(Fernandez et al., 2015). This study only includes services providing free to user or low out of pocket expenses. Additionally, we have included only services available to general adult service users. Accuracy of the data is dependent on the accuracy of the information provided by the services themselves.

"Salt and peppering" residential planning in ACT, which distributes public housing across all residential areas rather than in a congregate pattern as often found elsewhere, may confound the reliability of local area indicators in this region, due to its scattering effect on income and other indicators in geographic analysis.

\section{Conclusion}

The identification of common gaps and important differences in patterns of care between ACT and other jurisdictions highlights the relevance of an ecosystems approach to context analysis and service planning in mental health care at the local level, and the use of a standardised instrument able to provide valid comparisons in urban areas. We identified patterns of care present only in the Australian system such as a move away from Day Care services; as well as gaps common to all regions in the study such as alternatives to hospitalisation which suggest a lack of awareness at a global level of possible advantages of this type of care. Community based care was less developed in Australian than international regions.

These variations in service availability have implications for geographic and socio-economic equity of access to appropriate care, while commonalities between urban regions and differences between rural and urban areas also indicate the need for models of care sensitive to mental health care ecosystem indicators.

\section{Future Steps}

This information should be complemented with data on service utilisation, financing and quality indicators to support organisational learning. The incorporation of new knowledge into complex systems such as mental health care is important in both managing and making change, and is particularly relevant within the context of significant changes originating outside the system, such as those in Australia resulting from the new Mental Health Plan, the change to PHNs and the introduction of the National Disability Insurance Scheme( NDIS).

\section{Declarations}

Ethics approval and consent to participate: Perth North data was assessed as a QI project and ethics exemption received from the Northern Metropolitan Health Service MH Human Research Ethics Committee. ACT data: Ethics approval was granted by ACT Health HREC. Western Sydney data: Ethics approval was granted by University of Sydney HREC. South East Sydney data was retrieved from a previously published report

Consent for publication: Not applicable

Availability of data and materials: The datasets generated and/or analysed during the current study are available in the Repository at Centre for Mental Health Research, Australian National University https://rsph.anu.edu.au/research/projects/atlas-mental-health-care

Competing interests: The authors declare that they have no competing interests

Funding: This research has been supported by Capital Health Network and the Bupa Health Foundation- Australia.

Authors' contributions:. MF and LSC performed data collection and analysis; JSP and NB contributed data visualisation and analysis. MG and JM contributed to data analysis. LA reviewed paper and made substantial contribution to analysis. All authors have reviewed the final manuscript.

Acknowledgements: The authors would like to thank ACT Primary Health Network, the Western Australian Primary Health Alliance, particularly Dr Danny Rock, ACT Health particularly Mr Bruno Aloisi, the Western Sydney Primary Health Network, particularly Mr Bill Campos, the Central and Eastern Sydney Primary Health Network and the South East Sydney Local Health District and the respective steering committees for the Integrated Mental Health Atlases of the Australian regions. We would also like to thank the managers and planners of the MH system of Gipuzkoa, particularly Álvaro Iruin and Andrea Gabilondo, for the provision of data and support to develop the present study.

The present research study is frameworked in the REFINEMENT Spain project (Project PI15/01986), funded by the Carlos III Health Institute. We would also like to acknowledge the partners of the REFINEMENT project (REsearch on FINancing systems' Effect on the quality of MENTal health care - 7FP European Commission, Project number: 261459) specially Prof Kristian Wahlbeck (http://www.refinementproject.eu/participants.php); and the ChileSpain research consortium led by the Psicost Research Association funded by FONDECYT (National Fund for Scientific and Technological Development, Chile - research project \#1030605) and AECID (Spanish Cooperation Agency for International Development); specially Prof. Sandra Saldivia. 


\section{References}

2018 Revision of World Urbanization Prospects / Multimedia Library - United Nations Department of Economic and Social Affairs. (n.d.). Retrieved November 28, 2019, from https://www.un.org/development/desa/publications/2018-revision-of-world-urbanization-prospects.html

Astell-Burt, T., \& Feng, X. (2019). Association of Urban Green Space With Mental Health and General Health Among Adults in Australia. JAMA Network Open, 2(7), e198209-e198209. https://doi.org/10.1001/jamanetworkopen.2019.8209

Australia Urban Population Percent Of Total. (n.d.). Tradingeconomics.Com. Retrieved November 13, 2019, from https://tradingeconomics.com/australia/urban-population-percent-of-total-wb-data.html

Bagheri, N., Batterham, P. J., Salvador-Carulla, L., Chen, Y., Page, A., Calear, A. L., \& Congdon, P. (2019). Development of the Australian neighborhood social fragmentation index and its association with spatial variation in depression across communities. Social Psychiatry and Psychiatric Epidemiology, 54(10), 1189-1198. https://doi.org/10.1007/s00127-019-01712-y

Bixby, H., Hodgson, S., Fortunato, L., Hansell, A., \& Fecht, D. (2015). Associations between Green Space and Health in English Cities: An Ecological, Cross-Sectional Study. PLOS ONE, 1O(3), e0119495. https://doi.org/10.1371/journal.pone.0119495

CHN-Mental-Health-and-Suicide-Prevention-Plan.pdf. (n.d.). Retrieved July 25, 2020, from https://www.chnact.org.au/wpcontent/uploads/2020/02/CHN-Mental-Health-and-Suicide-Prevention-Plan.pdf

Department of Health. (2017). The Fifth National Mental Health and Suicide Prevention Plan. Commonwealth of Australia. http://www.coaghealthcouncil.gov.au/Portals/0/Fifth\%20National\%20Mental\%20Health\%20and\%20Suicide\%20Prevention\%20Plan.pdf

European Commission. (2016, November 25). EU-Compass for Action on Mental Health and Well-being [Text]. Public Health - European Commission. https://ec.europa.eu/health/non_communicable_diseases/mental_health/eu_compass_en

Fernandez, A., Salinas-Perez, J. A., Gutierrez-Colosia, M. R., Prat-Pubill, B., Serrano-Blanco, A., Molina, C., Jorda, E., Garcia-Alonso, C. R., \& SalvadorCarulla, L. (2015). Use of an integrated Atlas of Mental Health Care for evidence informed policy in Catalonia (Spain). Epidemiology and Psychiatric Sciences, 24(6), 512-524. https://doi.org/10.1017/S2045796014000511

Frank, G., Sundquist, K., \& Sundquist, J. (2004). Urbanisation and incidence of psychosis and depression: follow-up study of 4.4 million women and men in Sweden. British Journal of Psychiatry, 184, 293-298.

Furst, M. A., Gandré, C., Romero López-Alberca, C., \& Salvador-Carulla, L. (2019). Healthcare ecosystems research in mental health: a scoping review of methods to describe the context of local care delivery. BMC Health Services Research, 19(1), 173. https://doi.org/10.1186/s12913-019-4005-5

Furst, M. A., Salinas-Perez, J. A., Anthes, L., Bagheri, N., Banfield M, M., Aloisi B, \& Salvador-Carulla, L. (2018). The Integrated Mental Health Atlas of the Australian Capital Territory Primary Health Network region. https://www.chnact.org.au/integrated-mental-health-atlas-australian-capital-territoryprimary-health-network-region

Furst M, Reynolds J, Salinas JA, Tsou C, Rock D, Hopkins J, Bell T, Woods L, McLoughlin L, Stretton A, Mendoza J, Bagheri N, \& Salvador-Carulla L, (2018). The Integrated Atlas of Mental Health of the Perth North Primary Health Network Region. Australian National University and Western Australia Primary Health Alliance (WAPHA). https://rsph.anu.edu.au/research/projects/atlas-mental-health-care

Furst, M.C, Bagheri,N, \& Salvador-Carulla, L. (2020). An ecosystems approach to mental health services research. BJPsych International, In Press.

Furst, M.C.; Salinas-Perez, J.A.; Hopman, K.; Maas, C.; Fernandez, A.; Xu, T.; Alvarez-Galvez, J.;, Prigent, A.; Gandré, C.; \& Salvador-Carulla, L. (2016). The Integrated Mental Health Atlas of the Central and Eastern Sydney PHN Region. Annex 2: The Integrated Mental Health Atlas of the South Eastern Sydney Local Health District. Mental Health Policy Unit. Brain and Mind Centre. Faculty of Health Sciences. University of Sydney, Sydney.

Gandré, C., Gervaix, J., Thillard, J., Macé, J.-M., Roelandt, J.-L., \& Chevreul, K. (2017). The Development of Psychiatric Services Providing an Alternative to Full-Time Hospitalization Is Associated with Shorter Length of Stay in French Public Psychiatry. International Journal of Environmental Research and Public Health, 14(3). https://doi.org/10.3390/ijerph14030325

GLOCAL / Research School of Population Health. (n.d.). Retrieved February 22, 2020, from https://rsph.anu.edu.au/research/projects/glocal

Gutiérrez-Colosía, M. R., Salvador-Carulla, L., Salinas-Pérez, J. A., García-Alonso, C. R., Cid, J., Salazzari, D., Montagni, I., Tedeschi, F., Cetrano, G., Chevreul, K., Kalseth, J., Hagmair, G., Straßmayr, C., Park, A. L., Sfectu, R., Ala-Nikkola, T., González-Caballero, J. L., Rabbi, L., Kalseth, B., ... Group, F. the R. (2017). Standard comparison of local mental health care systems in eight European countries. Epidemiology and Psychiatric Sciences, 1-14. https://doi.org/10.1017/S2045796017000415

Helbich, M., de Beurs, D., Kwan, M.-P., O'Connor, R. C., \& Groenewegen, P. P. (2018). Natural environments and suicide mortality in the Netherlands: a cross-sectional, ecological study. The Lancet Planetary Health, 2(3), e134-e139. https://doi.org/10.1016/S2542-5196(18)30033-0

Page $8 / 15$ 
I-CIRCLE. (n.d.). International City and Urban Regional Collaborative. Retrieved November 13, 2019, from http://www.iimhl.com/icircle-homepage.html Iruin A, Ruiz M, \& Salinas JA. (2013). Atlas de Salud Mental de Gipuzkoa. San Sebastian: Unidad de Comunicación Hospital Universitario Donostia.

Kirkbride, J. B., Keyes, K. M., \& Susser, E. (2018). City Living and Psychotic Disorders-Implications of Global Heterogeneity for Theory Development. JAMA Psychiatry, 75(12), 1211-1212. https://doi.org/10.1001/jamapsychiatry.2018.2640

Krabbendam, L., \& van Os, J. (2005). Schizophrenia and Urbanicity: A Major Environmental Influence-Conditional on Genetic Risk. Schizophrenia Bulletin, 31(4), 795-799. https://doi.org/10.1093/schbul/sbi060

Kuo, F. E., Sullivan, W. C., Coley, R. L., \& Brunson, L. (1998). Fertile ground for community: Inner-city neighborhood common spaces. American Journal of Community Psychology; Macon, 26(6), 823-851. http://dx.doi.org.virtual.anu.edu.au/10.1023/A:1022294028903

Lederbogen, F., Kirsch, P., Haddad, L., Streit, F., Tost, H., Schuch, P., Wüst, S., Pruessner, J. C., Rietschel, M., Deuschle, M., \& Meyer-Lindenberg, A. (2011). City living and urban upbringing affect neural social stress processing in humans. Nature, 474(7352), 498-501. https://doi.org/10.1038/nature10190

Leginski, Croze C, \& Driggers J. (1989). Data standards for mental health decision support systems. A report of the task force to revise the data content and system guidelines of the mental health statistics improvement program. Washington,. University of Michigan Library.

Lora, A., Hanna, F., \& Chisholm, D. (2017). Mental health service availability and delivery at the global level: an analysis by countries' income level from WHO's Mental Health Atlas 2014. Epidemiology and Psychiatric Sciences, 1-12. https://doi.org/10.1017/S2045796017000075

Montagni, I., Salvador-Carulla, L., Mcdaid, D., Straßmayr, C., Endel, F., Näätänen, P., Kalseth, J., Kalseth, B., Matosevic, T., Donisi, V., Chevreul, K., Prigent, A., Sfectu, R., Pauna, C., Gutiérrez-Colosia, M. R., Amaddeo, F., \& Katschnig, H. (2018). The REFINEMENT Glossary of Terms: An International Terminology for Mental Health Systems Assessment. Administration and Policy in Mental Health, 45(2), 342-351. https://doi.org/10.1007/s10488-0170826-x

OECD_regional_typology_Nov2012.pdf. (n.d.). Retrieved February 16, 2020, from https://www.oecd.org/cfe/regionalpolicy/OECD_regional_typology_Nov2012.pdf

Pedersen, C. B., \& Mortensen, P. B. (2001). Evidence of a Dose-Response Relationship Between Urbanicity During Upbringing and Schizophrenia Risk. Archives of General Psychiatry, 58(11), 1039-1046. https://doi.org/10.1001/archpsyc.58.11.1039

Peen, J., Schoevers, R. A., Beekman, A. T., \& Dekker, J. (2010). The current status of urban-rural differences in psychiatric disorders. Acta Psychiatrica Scandinavica, 121(2), 84-93. https://doi.org/10.1111/j.1600-0447.2009.01438.x

Perkins, D., Farmer, J., Salvador-Carulla, L., Dalton, H., \& Luscombe, G. (2019). The Orange Declaration on rural and remote mental health. Australian Journal of Rural Health, 27(5), 374-379. https://doi.org/10.1111/ajr.12560

Recovery-oriented-community-mental-health-models-SAX-REPORT.pdf. (n.d.). Retrieved September 5, 2019, from https://www.aci.health.nsw.gov.au/_data/assets/pdf_file/0019/395002/Recovery-oriented-community-mental-health-models-SAX-REPORT.pdf

Refinement of the OECD regional typology: Economic Performance of Remote Rural Regions. (n.d.). Retrieved February 22, 2020, from https://www.researchgate.net/publication/254457435_Refinement_of_the_OECD_regional_typology_Economic_Performance_of_Remote_Rural_Regions Research School of Population Health. (2019). Atlas of Mental Health Care. https://rsph.anu.edu.au/research/projects/atlas-mental-health-care.

Romero-López-Alberca, C., Gutiérrez-Colosía, M. R., Salinas-Pérez, J. A., Almeda, N., Furst, M., Johnson, S., \& Salvador-Carulla, L. (2019). Standardised description of health and social care: A systematic review of use of the ESMS/DESDE (European Service Mapping Schedule/Description and Evaluation of Services and DirectoriEs). European Psychiatry, 61, 97-110. https://doi.org/10.1016/j.eurpsy.2019.07.003

Sadeniemi, M., Almeda, N., Salinas-Pérez, J. A., Gutiérrez-Colosía, M. R., García-Alonso, C., Ala-Nikkola, T., Joffe, G., Pirkola, S., Wahlbeck, K., Cid, J., \& Salvador-Carulla, L. (2018). A Comparison of Mental Health Care Systems in Northern and Southern Europe: A Service Mapping Study. International Journal of Environmental Research and Public Health, 15(6), 1133. https://doi.org/10.3390/ijerph15061133

Salinas-Perez, J. A., Salvador-Carulla, L., Saldivia, S., Grandon, P., Minoletti, A., \& Romero Lopez-Alberca, C. (2018). Integrated mapping of local mental health systems in Central Chile. Revista Panamericana de Salud Pública, 42. https://doi.org/10.26633/RPSP.2018.144

Salinas-Perez, J.-A., Gutierrez-Colosia, M. R., Furst, M.C, Suontausta,P, Bertrand,J, Almeda,N, Mendoza J, Rock D, Sadeniemi,M, Cardoso,G, \& SalvadorCarulla L,. (2020). Patterns of mental health care in remote areas: Kimberley (Australia), Nunavik (Canada) and Lapland (Finland). The Canadian Journal of Psychiatry/La Revue Canadienne de Psychiatrie.

Salvador-Carulla L, Fernandez A, Feng X, Astell-Burt, T, Maas, C., Smith-Merry, J., \& Gillespie, J. (2016). The Integrated Mental Health Atlas of Western Sydney. Mental Health Policy Unit, Brain and Main Research Institute, Faculty of Health Sciences, University of Sydney. Western Sydney Partners in 
Recovery, Sydney.

Salvador-Carulla, L., Haro, J. M., \& Ayuso-Mateos, J. L. (2006). A framework for evidence-based mental health care and policy. Acta Psychiatrica Scandinavica. Supplementum, 432, 5-11. https://doi.org/10.1111/j.1600-0447.2006.00914.x

Salvador-Carulla, Luis, Alvarez-Galvez, J., Romero, C., Gutiérrez-Colosía, M. R., Weber, G., McDaid, D., Dimitrov, H., Sprah, L., Kalseth, B., Tibaldi, G., Salinas-Perez, J. A., Lagares-Franco, C., Romá-Ferri, M. T., \& Johnson, S. (2013). Evaluation of an integrated system for classification, assessment and comparison of services for long-term care in Europe: the eDESDE-LTC study. BMC Health Services Research, 13(1). https://doi.org/10.1186/1472-6963$13-218$

Salvador-Carulla, Luis, Amaddeo, F., Gutiérrez-Colosía, M., Salazzari, D., Gonzalez-Caballero, J. L., Montagni, I., Tedeschi, F., Cetrano, G., Chevreul, K., Kalseth, J., Hagmair, G., Straßmayr, C., Park, A.-L., Sfetcu, R., Wahlbeck, K., \& Garcia-Alonso, C. (2015). Developing a tool for mapping adult mental health care provision in Europe: the REMAST research protocol and its contribution to better integrated care. International Journal of Integrated Care, 15(4). https://doi.org/10.5334/ijic. 2417

Salvador-Carulla, Luis, Saldivia, S., Martinez-Leal, R., Vicente, B., Garcia-Alonso, C., Grandon, P., \& Haro, J. M. (2008). Meso-level Comparison of Mental Health Service Availability and Use in Chile and Spain. Psychiatric Services, 59(4), 421-428. https://doi.org/10.1176/ps.2008.59.4.421

Sanches, S. A., Swildens, W. E., van Busschbach, J. T., \& van Weeghel, J. (2019). Identifying social participation subgroups of individuals with severe mental illnesses: a latent class analysis. Social Psychiatry and Psychiatric Epidemiology, 54(9), 1067-1077. https://doi.org/10.1007/s00127-01901704-y

Tomita, A., Vandormael, A. M., Cuadros, D., Di Minin, E., Heikinheimo, V., Tanser, F., Slotow, R., \& Burns, J. K. (2017). Green environment and incident depression in South Africa: a geospatial analysis and mental health implications in a resource-limited setting. The Lancet Planetary Health, 1(4), e152e162. https://doi.org/10.1016/S2542-5196(17)30063-3

Underhill C. (2018). Sliding towards mental health momentum at the World Economic Forum. Centre for Urban Design and Mental Health, 4:5. https://www.urbandesignmentalhealth.com/journal-4-davos.html

van den Berg, M., van Poppel, M., van Kamp, I., Andrusaityte, S., Balseviciene, B., Cirach, M., Danileviciute, A., Ellis, N., Hurst, G., Masterson, D., Smith, G., Triguero-Mas, M., Uzdanaviciute, I., Wit, P. de, Mechelen, W. van, Gidlow, C., Grazuleviciene, R., Nieuwenhuijsen, M. J., Kruize, H., \& Maas, J. (2016). Visiting green space is associated with mental health and vitality: A cross-sectional study in four european cities. Health \& Place, 38, 8-15. https://doi.org/10.1016/j.healthplace.2016.01.003

van Spijker, B. A., Salinas-Perez, J. A., Mendoza, J., Bell, T., Bagheri, N., Furst, M. A., Reynolds, J., Rock, D., Harvey, A., Rosen, A., \& Salvador-Carulla, L. (2019). Service availability and capacity in rural mental health in Australia: Analysing gaps using an Integrated Mental Health Atlas. Australian \& New Zealand Journal of Psychiatry, 53(10), 1000-1012. https://doi.org/10.1177/0004867419857809

Walsh, E. I., Chung, Y., Cherbuin, N., \& Salvador-Carulla, L. (2020). Experts' perceptions on the use of visual analytics for complex mental healthcare planning: an exploratory study. BMC Medical Research Methodology, 20(1), 1-9. https://doi.org/10.1186/s12874-020-00986-0

\section{Tables}

Table 1: Comparison of socio-economic and socio-demographic indicators of the study areas 


\begin{tabular}{|c|c|c|c|c|c|c|c|}
\hline Areas & $\begin{array}{l}\text { Australian Capital } \\
\text { Territory PHN }\end{array}$ & $\begin{array}{l}\text { Western } \\
\text { Sydney PHN }\end{array}$ & $\begin{array}{l}\text { Perth } \\
\text { North PHN }\end{array}$ & $\begin{array}{l}\text { South Eastern } \\
\text { Sydney LHD }\end{array}$ & (Gipuzkoa) & Talcahuano & $\begin{array}{l}\text { Helsinki- } \\
\text { Uusimaa }\end{array}$ \\
\hline Population & 403,468 & 947,672 & $1,055,697$ & 921,658 & 716,834 & 290,889 & $1,638,293$ \\
\hline Population density ${ }^{a}$ & 171.1 & $1,223.5$ & 354.9 & $1,820.3$ & 375.8 & $1,147.9$ & 180.1 \\
\hline Dependency index ${ }^{b}$ & 45.1 & 47.9 & 47.3 & 43.1 & 55.6 & 45.7 & 50.5 \\
\hline Ageing index ${ }^{c}$ & 64.5 & 53.4 & 70.1 & 91.6 & 142.8 & 63.5 & 99.7 \\
\hline Indigenous status (\%) ${ }^{d}$ & 1.6 & 1.5 & 1.4 & 0.9 & 0.0 & 8.8 & 0.01 \\
\hline Born overseas (\%) ${ }^{\mathrm{e}}$ & 26.5 & 44.3 & 36.4 & 37.1 & 8.8 & 0.6 & 11.2 \\
\hline Single-parent families $(\%)^{f}$ & 6.8 & 6.7 & 6.8 & 5.3 & $4.3^{1}$ & 14.7 & 14.3 \\
\hline Living alone (\%) ${ }^{g}$ & 8.9 & 5.1 & 8.3 & 9.0 & $10.2^{1}$ & 4.5 & 19.8 \\
\hline $\begin{array}{l}\text { Not married or in a de facto } \\
\text { relationship }(\%)^{\mathrm{h}}\end{array}$ & 51.9 & 46.9 & 51.2 & 55.1 & $62.3^{1}$ & NA & 78.9 \\
\hline Needing assistance $(\%)^{i}$ & 4.5 & 5.0 & 3.9 & 4.5 & NA & NA & NA \\
\hline Early school leavers (\%) & 74.4 & 65.3 & 62.6 & 71.3 & 78.9 & 72.3 & 72 \\
\hline $\begin{array}{l}\text { Personal income }<\$ 400 \text { per } \\
\text { week }(\%)^{k}\end{array}$ & 23.9 & 34.7 & 30.2 & 27.9 & NA & NA & NA \\
\hline Unemployment rate (\%)' & 4.5 & 6.0 & 5.8 & 3.7 & 13.2 & 8.6 & 7.4 \\
\hline IRSD (Australia $=1000)^{\mathrm{m}}$ & 1076.27 & 994.33 & 1045.04 & 1034.92 & NA & NA & NA \\
\hline $\begin{array}{l}\text { Psychological distress (K10) } \\
(\%)^{n}\end{array}$ & $10.8^{2}$ & $11.7^{2}$ & $9.5^{2}$ & $9.1^{2}$ & NA & NA & NA \\
\hline \multirow[t]{2}{*}{ Suicide rate $(x 100,000)^{\circ}$} & $9.1^{3}$ & $7.4^{3}$ & $11.9^{3}$ & $8.2^{3}$ & 9.8 & 11.7 & 13.0 \\
\hline & & & & & & & $\begin{array}{l}(\text { Bio-Bio } \\
\text { region })^{4}\end{array}$ \\
\hline
\end{tabular}

Sources: Australia: Australian Bureau of Statistics, 2016. Spain: Statistics National Institute, 2016; Finland: Statistics Finland, 2016; Chile: Statistics National Institute, 2017. Except for: ${ }^{1}$ Statistics National Institute (Spain), 2011; ${ }^{2}$ Public Health Information Development Unit, 2014-15; ${ }^{3}$ Public Health Information Development Unit, 2011-15; ${ }^{4}$ Statistics National Institute (Chile), 2011.

Indicator definitions:

a Inhabitants per $\mathrm{Km}^{2}$.

b Percentage of population aged below 15 years old and above 64 years old over population aged between 15 and 64 years old.

${ }^{\mathrm{c}}$ Percentage of population aged below 15 years old over population aged above 64 years old.

${ }^{d}$ Percentage of population who identified themselves as being of Australian Aboriginal and/or Torres Strait Islander over total population.

e Percentage of population born overseas over total population.

${ }^{f}$ Percentage of single parent families with children under 15 years old over total families.

g Percentage of people living alone over population aged above 14 years old.

h Percentage of people not married or in a de facto relationship over population aged above 14 years old.

i Percentage of population who has needed for assistance with core activities over total population

jYear 12 or higher education (\%) Percentage of population who reached Year 12 or equivalent of school over population above 14 years old

${ }^{k}$ Percentage of population earning less than $\$ 400$ per week, including those on negative incomes, over population above 14 years old.

I Percentage of unemployed population over the labour force. 
$\mathrm{m}$ Index of Relative Social Disadvantage Score (Australia=1000).

n Percentage of adults with very high levels of psychological distress as measured by the Kessler Psychological Distress Scale (K10).

${ }^{\circ}$ Rate of deaths from suicide and self/inflicted injuries (ICD-10 codes: X60-X84, Y87.0) per 100,000 population. ASR: Age Standardized Rate

Table 2 Diversity of Main Types of Care: Australian comparison

\begin{tabular}{|lllll|}
\hline $\begin{array}{l}\text { URBAN AREAS } \\
\begin{array}{l}\text { (Primary Health } \\
\text { Networks) }\end{array}\end{array}$ & $\begin{array}{l}\text { Provider } \\
\text { Organisations }\end{array}$ & $\begin{array}{l}\text { BSICs (Basic Stable Inputs of Care or Care } \\
\text { Teams) }\end{array}$ & $\begin{array}{l}\text { MTCs (Main Types of } \\
\text { Care) }\end{array}$ & $\begin{array}{l}\text { Diversity } \\
\text { Different types of } \\
\text { MTCs }\end{array}$ \\
\hline ACT & 41 & 110 & 122 & 38 \\
\hline PN & 71 & 224 & 231 & 45 \\
\hline WS & 33 & 117.8 & 127.4 & 31 \\
\hline SES & 40 & 150 & 169 & 40 \\
\hline
\end{tabular}

\section{Figures}

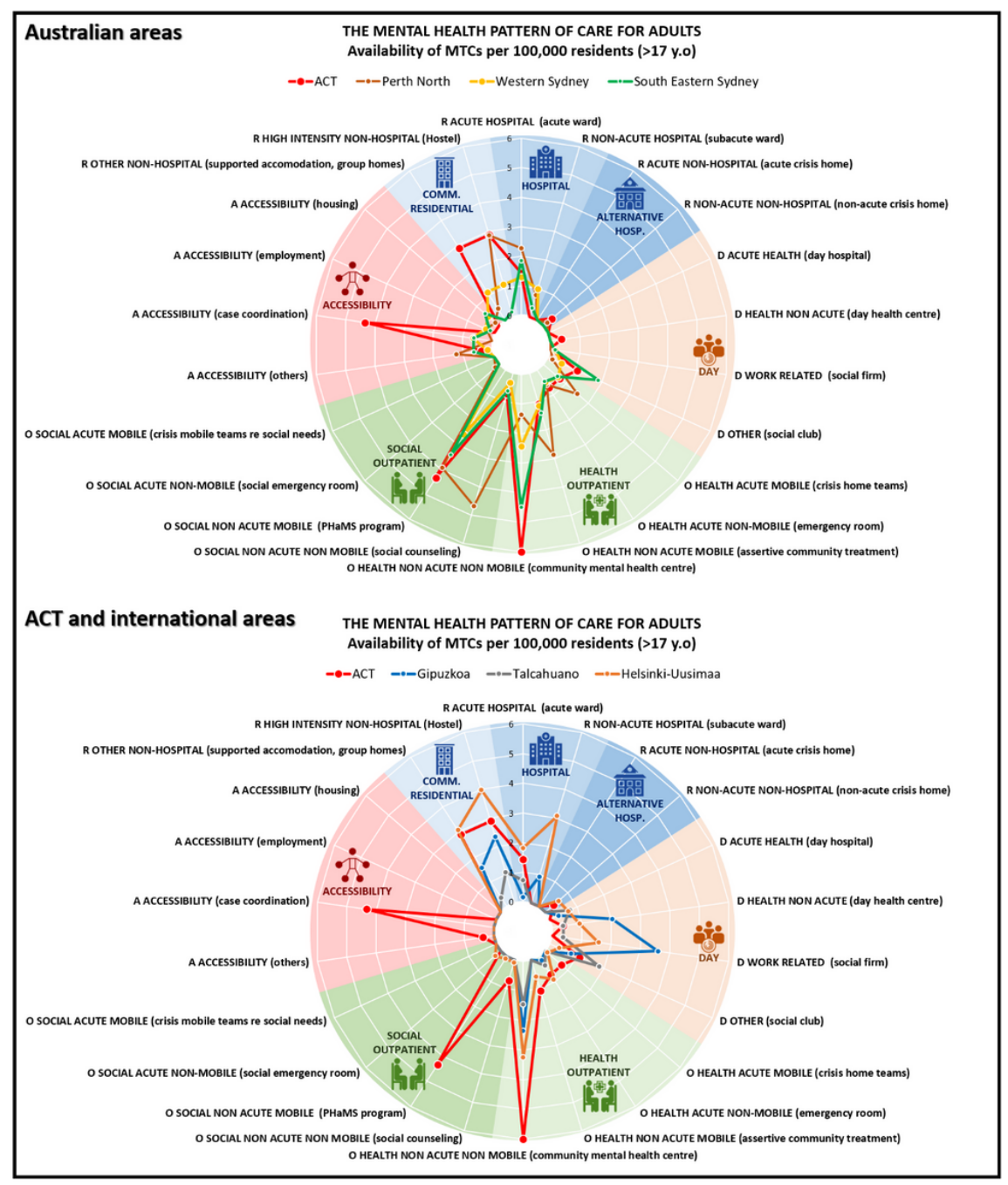

Figure 1

Main Types of Care per 100,000 adults: Australian and international comparison 


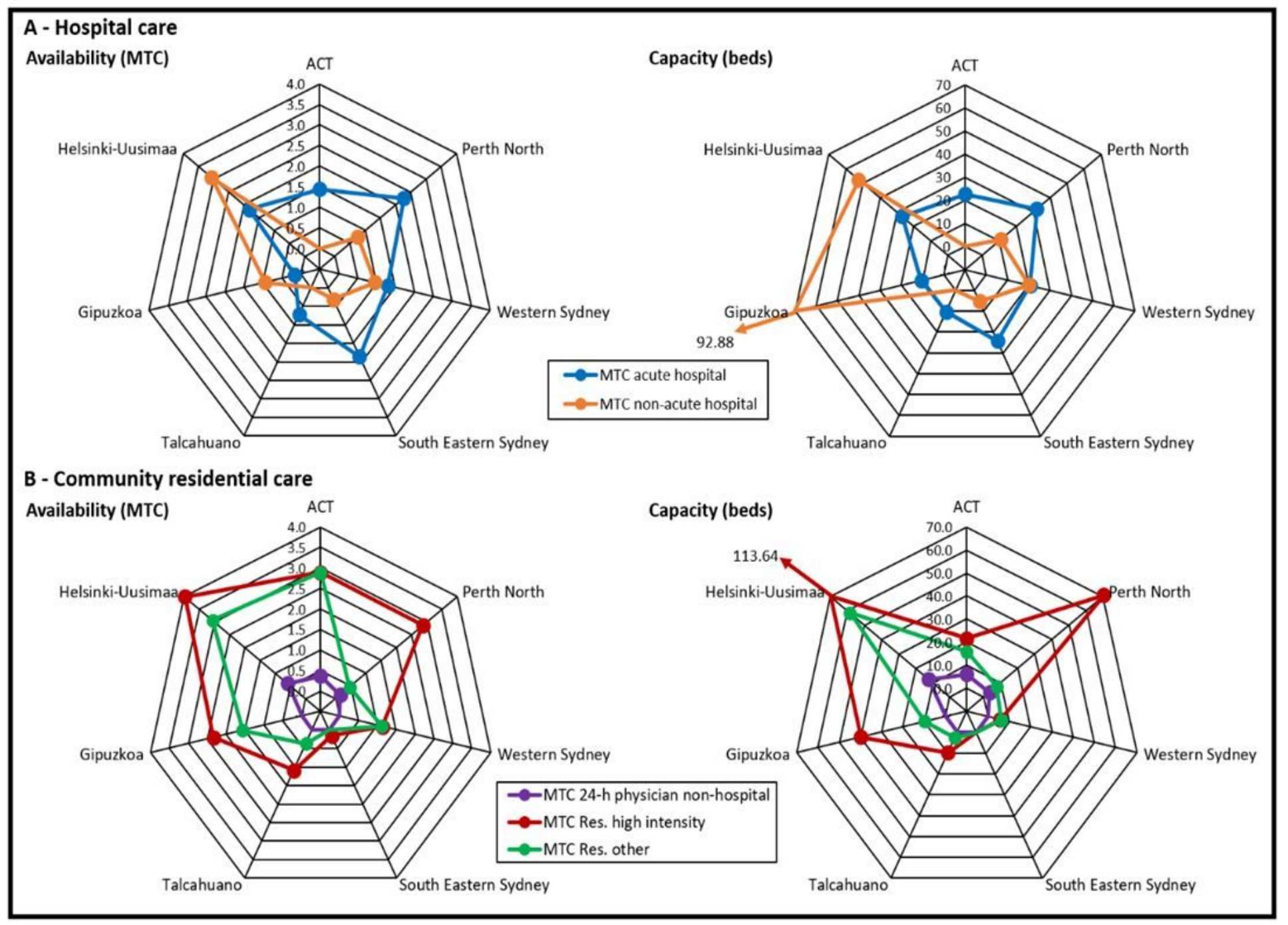

Figure 2

Residential Main Types of Care per 100,000 adults: Australian and international comparison 


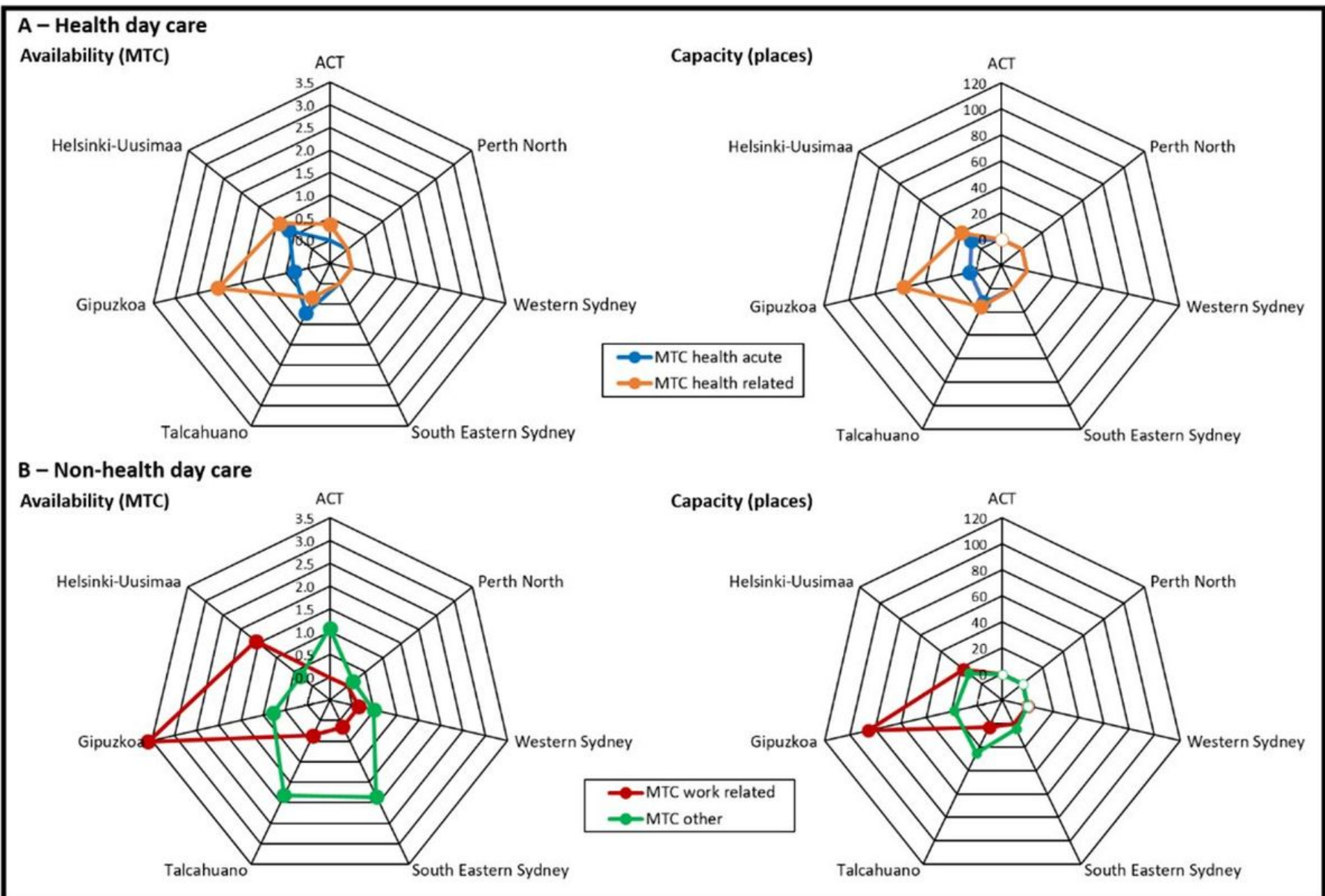

Figure 3

Availability of Day care Main Types of Care per 100,000 adults: Australian and international comparison 


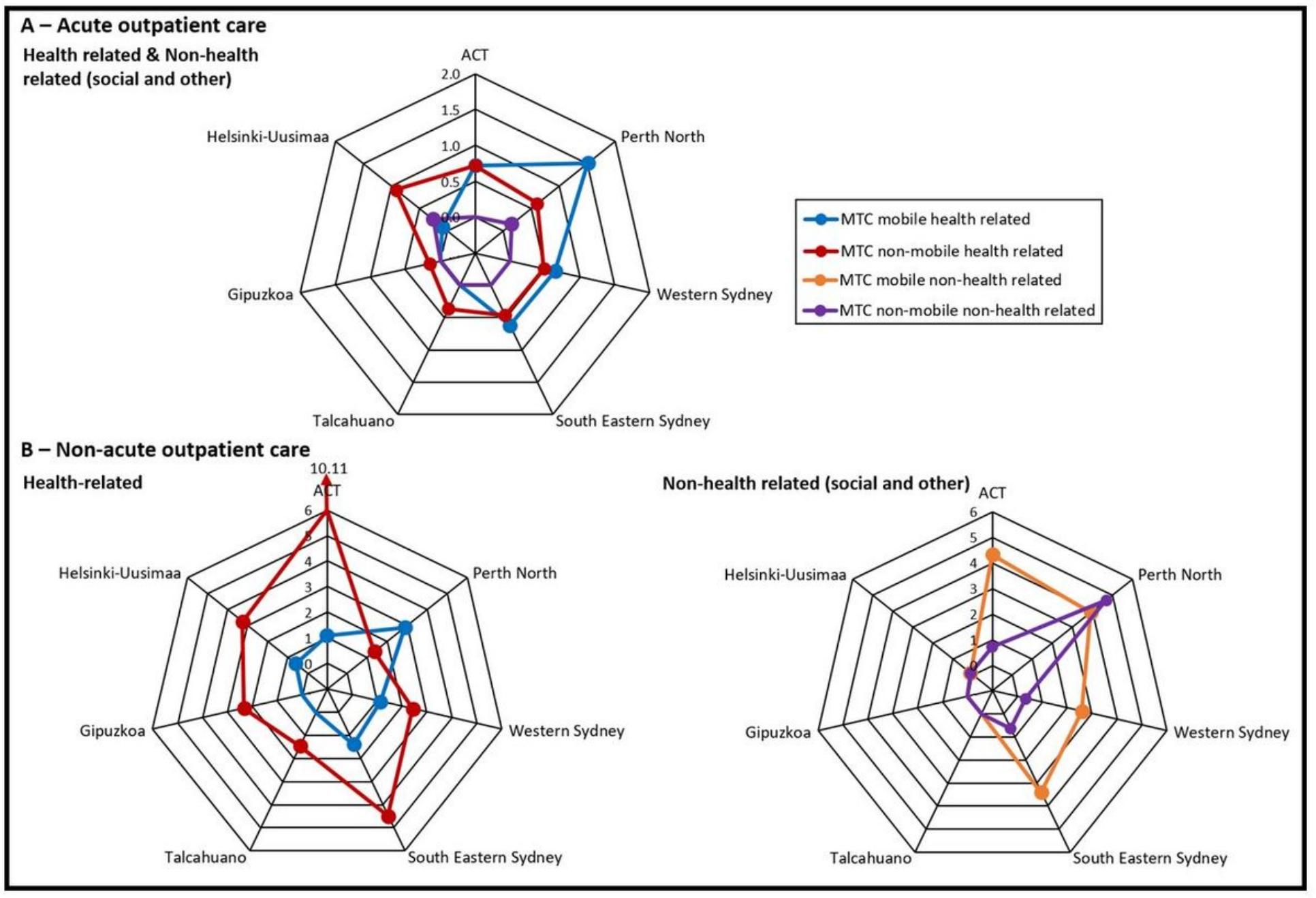

\section{Figure 4}

Availability of Outpatient Main Types of Care per 100,000 adults: Australian and international comparison 